\title{
POLÍCIA PARA QUEM PRECISA DE POLÍCIA: contribuições aos estudos sobre policiamento
}

\author{
INTRODUÇÃO
}

\author{
Jacqueline de Oliveira Muniz* \\ Eduardo Paes-Machado ${ }^{* *}$
}

O campo dos Estudos sobre Policiamento (Policing Studies) ${ }^{1}$ ou da Sociologia da Força Pública, como defendeu Jean Paul-Brodeur (2004), desenvolveu-se nos Estados Unidos, na segunda metade dos anos 60, e no Reino Unido, na década de 80, estendendo-se depois a outros países do mundo.

Em ambos os países, o interesse acadêmico pelo fenômeno do policiamento foi despertado pelas crises de hegemonia e erosão da legitimidade das agências policiais, resultantes da as-

* Antropóloga. Doutora em Ciência Política pelo IUPERJ/ UCAM. Professora do Mestrado em Direito da Universidade Cândido Mendes e da Graduação Tecnológica em Segurança e Ordem Pública (TECSOP) da Universidade Católica de Brasília - UCB.

Universidade Católica de Brasília. Qs 07, lote 01, epct, Bl. M sala 209 - Águas Claras - Taguatinga. Cep: 71966-700 Brasília, DF-Brasil. jacquelinedeoliveira.muniz@gmail.com

* *Professor de Sociologia da Universidade Federal da Bahia (UFBA). Doutor em Ciências Sociais pela UNICAMP (1992), com pós-doutorado na Universidade de Massachusetts (Estados Unidos), e nas Universidades de Toronto (Canadá) e Sheffield e Salford (Grã-Bretanha). epaesm@gmail.com

1 Esse campo de estudos integra, juntamente com a criminologia, a vitimologia e os estudos prisionais, uma área disciplinar mais vasta denominada de Criminologia (Reino Unido, Canadá e outros) ou Justiça Criminal (Estados Unidos). No Brasil, por sua vez, essa área está sendo chamada, é bem verdade que com algumas divergências entre os estudiosos, de Segurança Pública e Sociedade. censão de movimentos sociais de negros, pacifistas e operários desempregados. Dessas mobilizações e das respostas policiais violentas que lhes foram dadas de modo frequente emergiram grandes debates públicos acerca do papel dessas agências como violadoras de direitos.

Tais questionamentos se perderiam, provavelmente, em generalidades, ou não gerariam uma vertente produtiva de pesquisa sobre a polícia, não fosse a crescente irradiação intelectual da teoria da rotulação (ou reação social), com seu foco nas instituições disciplinares e agências de controle social (Becker, 1963). Segundo esta abordagem, tais agências têm um papel paradoxal, porque contribuem ativamente para produzir comportamentos desviantes e delituosos que deveriam, por princípio, coibir. Ao chamar a atenção para a autonomia relativa das agências de controle social para decidirem, interpretarem e aplicarem códigos normativos e legais segundo critérios próprios e valores dominantes na sociedade, a teoria da rotulação contribuiu para a construção conceitual do poder discricionário e do uso (policial) da força, os quais apresentam- 
se como as chaves definidoras para os estudos sobre policiamento. ${ }^{2}$

Não é de estranhar, assim, que os estudos sobre policiamento - com seu foco em práticas capilares de governo, operadas por "políticos de esquina”, como foram denominados os policiais (Muir Jr., 1977), e capazes de influenciar as percepções de cidadania - sejam liderados, no mundo e igualmente no Brasil, por cientistas sociais ${ }^{3}$ (Manning, 2005). Nessa linha, e como bem disse David Garland a respeito da criminologia, os estudos sobre policiamento usam amplamente as teorias, métodos e técnicas de pesquisa das ciências sociais. Dado o seu caráter poroso e intersticial, eles se nutrem e, ao mesmo tempo, contribuem para abrir perspectivas, experimentar e agregar conhecimentos aos repertórios dessas disciplinas.

Mais parecidos com certas divindades hindus, com múltiplos membros, caras e cabeças, do que com os monólitos celtas, o policiamento e a polícia são fenômenos complexos que, na suas inter-relações com outras expressões de controle, regulação e coerção, constituem um terreno de pesquisa fascinante e desafiador. Para o entendimento deste campo, vale a pena retomar a diferença central, ainda pouco compreendida entre nós, entre policiamento e polícia e propor uma tipologia das modalidades assumidas por esses fenômenos, capaz de subsidiar a sua compreensão na sociedade brasileira.

${ }^{2}$ A exemplo de qualquer ciência social, os estudos sobre policiamento abrigam duas vertentes: uma teóricointerpretativa e crítica - a Sociologia da Polícia - e outra gerencial-administrativa - a Sociologia para a Polícia (Manning, 2005).

${ }^{3}$ No Brasil, os primeiros estudos sobre policiamento foram feitos por Luis Paixão, da UFMG, no começo dos anos 80 , e vêm se expandindo desde então por conta da redemocratização política, da participação das universidades em cursos de formação policial e do desenvolvimento de programas de pós-graduação e pesquisa. Ao lado disso, não é supérfluo acrescentar que a tradução e publicação de uma grande coleção de textos internacionais sobre a temática, pela Editora da Universidade de São Paulo, com o patrocínio da Fundação Ford, no primeiro quinquênio do ano 2000, contribuiu para alargar a sua compreensão pelos pesquisadores brasileiros. Segundo um estudo recente, das 8.205 dissertações e teses de doutorado indexadas pela palavrachave "segurança pública", elaboradas nas universidades brasileiras, entre 1983 e 2006, 10\% (ou 822 destes trabalhos) tiveram por tema a polícia Lima, 2010).

\section{POLICIAMENTO}

O fenômeno do policiamento tem a sua inteligibilidade articulada à noção de controle social e suas dinâmicas descontínuas na vida social. Nesse recorte, ele pode ser visto como um expediente particular de controle pela ênfase no seu caráter instrumental, isto é, na sua capacidade de produzir efeito inibitório e o mais imediato possível sobre os acontecimentos e as atitudes de indivíduos e grupos. Constitui-se como um variado repertório de meios (vigiar, regular, impor, fiscalizar, patrulhar, guardar, conter, etc.), aplicados através de certos modos, para determinados fins: a sustentação de um status quo, de uma determinada visão e expectativa de ordem que se deseja obedecida e, em alguma medida, consentida pelos indivíduos ou grupos policiados.

A natureza política do policiamento, como bem assinalou Reiner (2004), se expressa em um agenciamento de meios visando a sustentar o exercício de certos tipos de poder e de autoridade, que podem ir do extremo da sujeição à obediência negociada. Se isso serve como ponto de partida, então pode-se afirmar que os estudos sobre policiamento contribuem para melhor compreender os dispositivos de coerção e coesão social e seus efeitos, e, com isso, distinguir as práticas sociais de controle e regulação, seus sentidos e funcionalidades, já que nem todo expediente de controle corresponde às formas instrumentais de policiamento.

O policiamento caracteriza-se, assim, como uma expressão pragmática, funcional, utilitária e invasiva do como sustentar a submissão, sob algum consentimento, às regras do jogo, vistas como objeto de enforcement (ou aplicação da lei), ou a uma determinada ordem pactuada ou não, com o recurso à coerção respaldada pela força. Observados no seu plural, especialmente nas sociedades complexas, os policiamentos e suas práticas ultrapassam a administração do Estado, sendo-lhe historicamente anteriores. Tal evidência é relevante, uma vez que se podem reconhecer práticas de policiamento em socie- 
dades sem Estado, assim como práticas de policiamento que não são administradas por agências estatais.

A anterioridade das práticas de policiamento à emergência de burocracias especializadas e estatais na sua administração, põe em relevo duas questões caras à compreensão desse conjunto de práticas sociais de controle e regulação (Bayley, 2002; Reiner, 2004). A primeira, é a de que o policiamento não constitui um lugar hegemônico do Estado. Sobretudo quando se considera que a ambição do Estado, desde seu surgimento, é o monopólio legal e legitimo da força e, por conseguinte, das práticas de policiamento que expressam e sustentam sua soberania sobre um determinado território e população, assim como dos dispositivos de governo, sobretudo as forças armadas e polícia, as quais são objeto de uma espécie de duopólio. A segunda, como decorrência, é que as agências especializadas estatais, as polícias, também não possuem, ainda que isso não seja abertamente assumido, por uma estratégia de legitimação e ampliação de poder, o monopólio das práticas de policiamento.

A possibilidade de uma teoria do policiamento e da polícia começa com essa distinção, posto que ela permite compreender que, por um lado, a polícia não se explica por suas funcionalidades ou aplicações e, por outro, que o policiamento não é apenas uma expressão de governos estatais. Em poucas palavras, em lugar de estar restrita a uma única organização, a polícia pública e estatal, a atividade de policiamento é realizada por uma vasta gama de organizações e arranjos coletivos.

\section{POLÍCIA E CIDADANIA}

Dentre a miríade de formas histórico-sociais e culturais assumidas pela atividade de policiamento está a polícia pública e estatal, uma "criatura" nascida há pouco mais de duzentos anos atrás, na Europa Ocidental, e que, de lá para cá, cresceu e se multiplicou em outras par- tes do mundo. Naquele momento histórico, a força policial nasceu para substituir as forças militares que, segundo o modelo de defesa da soberania (Foucault, 2003), mantinham a ordem pública nas grandes cidades. Tal modelo não combinava bem com as novas práticas de governo - fundadas na disciplina e na normatização, e na consequente normalização das condutas dos novos sujeitos sob domesticação, constituídos como indivíduos e cidadãos, isto é, como atores políticos e morais autônomos.

Estamos falando aqui da redefinição de um tipo de governo, de ambição democrática e liberal, e da construção da polícia, como um corpo especial de funcionários - uniformizados e armados ou não -, para fazer o trabalho de manutenção da ordem entre e por sobre os corpos e territórios. Trata-se da fabricação de dispositivos coercitivos imediatos e, ao mesmo tempo, indiretos, cujo objetivo era o de comunicar a substituição da violência deliberada e a administração de sua escassez por meios legítimos de força, em nome da emergência de uma forma de governar capaz de conduzir de perto e à distância (governance at a distance) as comunidades nacionais. Tamanha mudança nos processos de governo e de estabilização do exercício de poder tem implicações fundamentais no tocante aos modos, aos meios e aos fins relacionados à produção de obediências, agora sob algum consentimento, e suas estratégias de legitimação.

Em contraste com a doutrina da força máxima que norteia as forças armadas, a polícia pauta sua atuação pelo princípio da força mínima, visando a sustentar um determinado pacto político, assentado sob direitos e garantias, que se deseja construído com ou sob a autorização de indivíduos ou grupos policiados (Brodeur, 2004). Dito de outra maneira, busca-se garantir uma forma estatal e estável de governo, afirmando e restituindo os limites sobre os usos e abusos de poder entre os indivíduos e deles com o próprio Estado e seus agentes, sob o império da lei.

Contudo, em muitas sociedades contemporâneas - sobretudo as pós-coloniais, com escassa tradição democrática ou profundas 
clivagens sociais e étnicas -, as organizações policiais seguem abertas às dinâmicas pré-modernas ou tradicionais de proteção, reproduzindo práticas desiguais, discriminatórias e excludentes sobre uma parcela da população colocada à margem, ou situada na periferia do pacto social. ${ }^{4}$ Nesse cenário de desigualdade em direitos, as flutuações do crime e a percepção generalizada de insegurança, assim como os seus impactos sobre a opinião pública, reforçam a aprovação coletiva de práticas heterodoxas de policiamento público e estatal, nas quais se incluem toda sorte de violações e violências socialmente autorizadas.

Diante desta perspectiva, a reflexão sobre a polícia não pode desconsiderar as diversas faces assumidas por essa complexa organização em suas expressões de governo: um dispositivo de dominação (de classe, raça, gênero e geração), uma instância produtora e distribuidora de moral e "moralismo" conflitantes, um instrumento de sustentação de direitos a serviço de uma cidadania mais ou menos inclusiva e em processo continuado de afirmação, e um meio de força orientado por fins coletivos e atravessado por seus interesses corporativos.

Pode-se afirmar, então, que a relação da polícia com a cidadania é de complementaridade, que se evidencia em um jogo de negociação de verdades, de afirmação e negação, de legitimação e deslegitimação diante da ordem político-social ambicionada ou do escopo do pacto construído, se para alguns ou para todos. A relação da polícia com a cidadania revela, assim, uma tensão criadora e criativa que põe em relevo os modos concretos do governar e seus efeitos em uma dimensão mais sensível e crítica: o exercício autorizado do poder coercitivo ali "nas esquinas",

${ }^{4}$ Mesmo em contextos onde as organizacões policiais estão conformadas pelos princípios democráticos da igualdade e imparcialidade da ação coercitiva do Estado, sob a universalidade das regras do jogo, como nas sociedades do hemisfério norte-ocidental, a atuação policial pode vir a fortalecer, mediante orientação de governo, clivagens sociorraciais e políticas entre indivíduos e grupos, discriminando segmentos sociais percebidos como perigosos indesejáveis ou estrangeiros, em seu próprio território. A escala desses abusos e excessos da polícia, entretanto, está muito aquém da escala que se verifica em sociedades menos inclusivas, do ponto de vista dos direitos de cidadania, como a brasileira. entre nós, que explicita, questiona e redefine os limites e os sentidos do fazer policial pela afirmação de direitos constituídos ou na emergência de direitos difusos e novos direitos. Nessa linha, o fiel da balança depende sempre e mais do que de outras variáveis - a exemplo do nível de escolaridade e do treinamento dos policiais da orientação governamental, no sentido de limitar ou não o potencial das forças policiais para "invadirem a cerca" ou solaparem os princípios democráticos, bem como da consciência (Cheviny, 1995) e do grau de universalidade dos direitos de cidadania nas sociedades (Ivo, 2008).

\section{PARA UMA ANÁLISE DO POLICIAMENTO}

Ao contrário dos prognósticos que apontam uma tendência crescente de estatização das práticas de controle e vigilância, os policiamentos apresentam um caráter mais plural, fragmentado e privatizado nas sociedades contemporâneas (Johnston, 2002). Esse também é o padrão no Brasil, onde novos arranjos de policiamento, representados pela proliferação das mais diversas formas de segurança privada, como mostra Martha K. Huggins, neste Dossiê, articulam-se e revigoram velhas modalidades de controle social privado, informal e, muitas vezes, violento. Como não poderia deixar de ser, as práticas públicas e privadas de policiamento alimentam-se de espaços de alegalidade e, especialmente, das ilegalidades populares ou ilegalismos tolerados que atravessam de alto a baixo a sociedade brasileira. A isso se agregam as chamadas "visões de mercado", tomadas como expressões de modernidade e trazidas pelos processos neo-liberais de desregulamentação e promoção do empreendedorismo na produção e distribuição de coercitividades consentidas.

Dentre os distintos eixos que podem estruturar as possibilidades lógicas e históricas de arranjos de policiamento em sociedades complexas, parece oportuno entender esse universo a partir de um enquadramento tridimensional que 
elege os seguintes atributos para ordenar suas prováveis variações empíricas: (i) administração ou governo (estatal e não-estatal); (ii) espaço ou território (público e privado); e (iii) referência normativa (legal ou ilegal).

Busca-se, com esse enquadramento, possibilitar generalizações ou ampliar o alcance conceitual-explicativo dos estudos de caso e análises qualitativas. Da combinatória desses atributos, chega-se a uma matriz de análise qualitativa de propriedades que integra quatro conjuntos que se desdobram em oito tipos lógicos de práticas, entre o legal e o ilegal, que pretendem dar conta do maior número possível de evidências empíricas, assim como dos seus inevitáveis hibridismos. Isso é o que pode ser visualizado na matriz de análise apresentada a seguir. comum, com mandatos legalmente estabelecidos, como os realizados pela Polícia Militar, Civil, Federal e Guarda Municipal etc.;

- Policiamento estatal ilegal e público, representado pelos policiamentos administrados ou feitos por agentes estatais em áreas públicas ou espaços de uso comum, sem mandato legalmente estabelecido, a exemplo daqueles implementados por empresas e grupos de vigilância clandestina que praticam extorsão continuada (racketeering). Amplamente disseminada nas cidades brasileiras, esta modalidade de policiamento estatal ilegal se expressa em toda a sua plenitude nas milícias no Rio de Janeiro.

O segundo conjunto circunscreve as práticas de policiamento não-estatal e em espaços

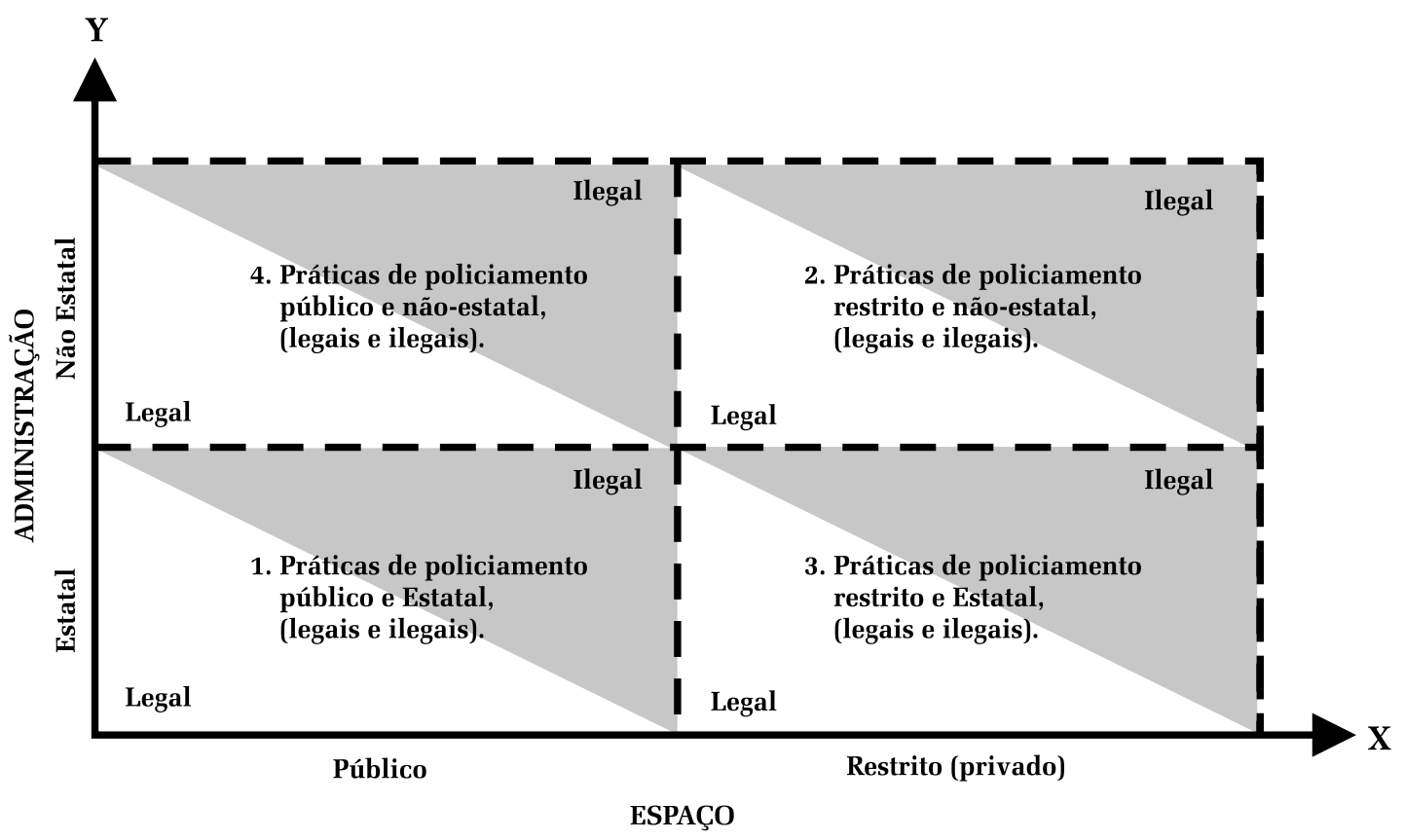

O primeiro conjunto agrega as práticas de restritos, que dizem respeito àqueles policiamenpoliciamento estatal e público, que dizem res- tos feitos em locais privados ou de circulação peito aos policiamentos feitos em locais de uso restrita, sob a administração de agentes não-escoletivo, sob a administração de agentes contra- tatais ou privados. Esse conjunto de evidências tados e pagos pelo Estado. Esse conjunto de evi- se desdobra em dois subconjuntos:

dências se desdobra em dois subconjuntos:

- Policiamento estatal legal e público, a exemplo dos policiamentos administrados por agentes estatais em áreas públicas ou espaços de uso
- Policiamento não-estatal legal em espaços privados, no qual se incluem os policiamentos respaldados por competências legais e realizados por agentes particulares em espaços de cir- 
culação restrita ou privados: segurança privada bancária, brigadas de emergência de empresas, vigilância de condomínios, escolta pessoal, segurança de grandes eventos, clubes, detetives particulares regularizados, etc.;

- Policiamento não-estatal ilegal em espaços privados, cujos arranjos reportam-se aos policiamentos sem respaldo legal, realizados por agentes particulares em espaços de circulação restrita ou privados, os quais são ilustrados pelas ligas comunitárias de autodefesa, vigilância informal ou clandestina em condomínios, restaurantes, boates, propriedades rurais, escoltas efetuadas por "capangas", vigilantes particulares informais, "arapongas", "leões de chácara" etc..

O terceiro conjunto congrega as práticas de policiamento estatal em espaços restritos. Refere-se aos policiamentos feitos em espaços de circulação restrita ou privados sob a administração de agentes do Estado. Esse conjunto de evidências se desdobra em dois subconjuntos:

- Policiamento estatal legal em espaços de circulação restrita, como, por exemplo, os policiamentos feitos por agentes públicos e com respaldo legal em museus, palácios, residências oficiais, Congresso Nacional, prisões, universidades públicas, empresas estatais, instalações das forças armadas etc.;

- Policiamento estatal ilegal em espaços de circulação restrita, exemplificado pelos policiamentos realizados sem autorização legal, em espaços de circulação restrita ou privados, por funcionários públicos, tais como policiais, bombeiros, agentes penitenciários que fazem o chamado "bico" na vigilância privada informal em locais de lazer, centros comerciais, eventos, condomínios, etc..

O quarto conjunto conforma as práticas de policiamento não-estatal em espaços públicos, que incluem o policiamento de espaços públicos ou de uso coletivo, sob a administração de agentes privados. Esse conjunto de evidências se desdobra em dois subconjuntos:

§ Policiamento não-estatal legal em espaços pú- blicos, que diz respeito aos policiamentos implementados com respaldo legal por agentes particulares ou privados, em espaços públicos ou de uso coletivo, como as práticas de controle e vigilância feitas moradores, vizinhos, proprietários rurais, etc..

§ Policiamento não-estatal ilegal em espaços públicos, que se refere aos policiamentos realizados sem respaldo legal por agentes particulares ou privados em espaços públicos ou de uso coletivo, ilustrados pelas práticas de controle e vigilância feitas por ligas comunitárias de autodefesa, milícias, bandos armados, gangues, grupos de extermínio, capangas, etc..

Essas oito possibilidades lógicas permitem explorar tanto os tipos puros, como as suas combinações, a exemplo de: (i) "milícias" compostas por agentes do Estado, que fazem policiamento público e privado ilegal e praticam extorsão continuada; (ii) bandos armados, que fazem policiamento público e privado não-estatal; (iii) agentes públicos, cedidos legalmente para atividades de policiamento privado em agências bancárias, de pessoas ameaçadas, eventos culturais ou esportivos, etc.; e (iv) atores privados ou terceirizados que, por meio de concessões legais ou parcerias público-privadas, fazem policiamento público como os agentes de trânsito, vigilantes e fiscais nos arredores de rodoviárias, aeroportos, metrô, etc.

Ainda em relação à proposta de modelagem dos tipos de policiamento, é oportuno destacar que o eixo relativo à legalidade das práticas de policiamento de pessoas e territórios, nos termos do ordenamento jurídico-político em vigor, contribui para indagar sobre as dimensões do que seja a práxis do consentimento de quem e para quem policiar, um requisito fundamental para se problematizarem as coercitividades e suas formas de obediência até o limite da pura opressão. Permite, por conseguinte, compreender as instâncias de fabricação de normatividades que orientam os mandatos de policiamento, suas expressões formais, seus limbos e suas imprecisões, de maneira a salientar as práticas coercitivas que continuam informais e alegais, por au- 
sência de previsão legal.

Por sua vez, o eixo da legalidade dos modos e meios de policiar, transversal aos conjuntos de policiamento, remete ao consentimento em sua expressão de legitimidade. Tem-se, aqui, a oportunidade de apreender os arranjos concretos de policiamento, explorando as tensões próprias de sociedades complexas e plurais entre legalidades e legitimidades que se põem, na ordem prática, em conflito. Sob essa perspectiva, podem-se apreciar, por exemplo, práticas ilegais de policiamento legitimadas por certos grupos sociais para si ou para os outros. Ou mesmo práticas legais de policiamento desautorizadas ou deslegitimadas por alguns ou por todos.

Ao se tomar o consentimento para policiar em suas dimensões legais e legítimas como uma chave problematizadora, abre-se a possibilidade de uma reflexão mais sensível acerca dos processos de construção da tolerância e dos níveis de aceitação dos indivíduos e grupos policiados em sociedades com Estado. Como resultado, pode-se avançar no entendimento da sutil fronteira entre obediência e sujeição e suas implicações sobre as formas de construção e exercício de autoridade e seus assentimentos.

A combinatória de tipos de policiamentos, aqui proposta como um insumo para uma agenda de pesquisas, pretende contribuir para o diálogo entre os estudos de caso sobre as práticas de policiamento. Também sugere algumas pistas iniciais que, com o auxílio da combinação hipotética de atributos ou variáveis generalizáveis, superem o confinamento analítico do que se apresenta como casuístico, e ultrapassem o risco de substantivação do que se mostraria como específico ou singular. Ao se procurar circunscrever o universo dos arranjos de policiamento em sua diversidade, dando conta de suas alternativas lógicas possíveis, resta-nos o trabalho de inventariar e teorizar sobre suas evidências empíricas.

Os artigos aqui reunidos mostram a riqueza, diversidade e avanços dos estudos sobre policiamento em vários países das Américas e da Europa - Argentina, Brasil, Estados Unidos,
Holanda e Venezuela. Todos eles iluminam aspectos escassamente estudados ou relativamente obscuros do tema em tela, apontando perspectivas e focando recortes de análise que, seguramente, despertarão interesse entre pesquisadores e operadores de segurança pública do país. Os temas dos seis artigos são: a tomada de decisão policial, a gestão de multidões, a guarda municipal, a cultura policial, o castigo e as tendências do policiamento público e privado no Brasil. Outro aspecto digno de nota, considerando a imagem austera dos estudos sobre policiamento, é que cinco dos oito autores desses trabalhos são mulheres.

Jacqueline Muniz e Washington da Silva abordam o exercício do mandato policial em João Pessoa, chamando a atenção para as demandas da população no âmbito da sustentação da ordem pública: conflitos, incivilidades e desordens, pequenos e grandes delitos. Dado que todas apresentam algum nível de risco potencial ou concreto, os policiais usam, com graus distintos de poder decisório e distribuição gradativa de coercitividades, sua capacidade discricionária para tomar decisões acerca dos meios e modos para a produção consentida de soluções razoáveis.

Como colocam os autores: "A expectativa social que se tem em relação ao decisionismo policial corresponde ao desafio e à complexidade do lugar de polícia. Particularmente nas sociedades de democracia emergente como a brasileira, em que a produção de obediências consentidas, com o recurso potencial e concreto de força, sob império da lei, segue, ainda, como um 'cheque em branco' ou uma 'procuração em aberto', tem-se tanto a subestimação quanto a superestimação do decidir e agir policiais. Essa ambição, para mais ou para menos, quanto ao dever-ser policial, muitas vezes extrapola os limites do que seriam os contornos do seu mandato público, em termos do que se aspira como legal, legítimo, politicamente autorizado, tecnicamente válido e aceito coletivamente.".

O trabalho dos policiais que patrulham as ruas está orientado por um pragmatismo pru- 
dente, seja em relação às características e circunstâncias que informariam as ocorrências criminais e não-criminais, seja em relação às formas pelas quais o lugar da autoridade policial é, na prática, constituído e negociado. "Nessa busca por uma boa medida, algum agir consentido e que faça sentido para os envolvidos, sob o 'espírito da lei', constatou-se que, quando se trata de questões criminais violentas, consideradas de maior gravidade, a tendência dos policiais é dar um encaminhamento formal, conduzindo os envolvidos para a delegacia de polícia, para o devido processo legal. Já nas situações criminais de menor gravidade e não-criminais, que conformam a maior parte do chamamento à polícia, observou-se que os PMs da ponta da linha buscam fazer, desde que não haja risco iminente, uso de expedientes informais e alegais de tomada de decisão, resolvendo no local, harmonizando, conciliando, advertindo ou orientando os envolvidos."

Os sentidos atribuídos à "autoridade consentida”, legal e legítima, são atravessados por apetites oportunos e oportunistas de particularização. Em seus próprios termos: "Na prática, o poder do policial tende a ser intencionalmente menor que a amplitude formalmente estabelecida no poder de polícia. Inseguros, política e institucionalmente, quanto aos termos pactuados do seu mandato público, os policiais militares escolhem poder de menos, dramatizando que até podem de mais para sobreviver entre as 'carteiradas' que recebem dos seus variados 'patrões'. Por isso, estão sempre dispostos a passar o bastão das ocorrências para outrem, da forma mais rápida, segura e razoável.”

Como única ilustração, neste Dossiê, da chamada Sociologia para a Polícia, Otto Adang, psicólogo social e especialista em gestão de multidões, discute um tema que, além de sua relevância para os eventos futebolísticos e festivos nacionais regulares, despertará atenção dos operadores brasileiros da segurança pública, com a aproximação da Copa do Mundo e das Olimpíadas - o policiamento das grandes partidas de futebol. No seu estudo sobre os métodos de policiamento - brandos e duros, de baixo e alto perfil - empregados nos campeonatos europeus de futebol de 2000 e 2004, Adang retoma a contribuição inovadora de McPhail (1991) sobre o comportamento das massas. Ao contrário das teorias tradicionais ao estilo de Le Bon, que explicam esse comportamento apenas por processos internos e assumem que a patologia de alguns contamina todo o grupo, McPhail enfatizou que as multidões não formam uma massa homogênea de indivíduos que se comportam da mesma maneira. Para ele, por exemplo, não está provado que as pessoas reunidas em grupos tenham mais probabilidade de usar a violência do que em outras circunstâncias cotidianas, ou que as multidões manifestem uma maior tendência a se comportar de modo emocional ou irracional.

A “desordem” coletiva só se torna possível graças à proeminência psicológica compartida, resultante de uma dinâmica de interações entre os participantes do grupo, de uma identidade comum. A partir de uma perspectiva psicológica, para que isto aconteça, é preciso que a polícia trate uma multidão inicialmente heterogênea como um todo homogêneo, levando os seus integrantes a se perceberem como membros de uma categoria comum e, por conseguinte, desencadeando um ciclo de tensão e agravando o conflito com a polícia.

Em contraste com isso, Adang sublinha a necessidade de se levarem em conta as diferentes identidades e maneiras de atuar e reagir dos grupos reunidos. No fundamental, é preciso distinguir as pessoas com base no que realmente estão fazendo, e não apenas em função, como é hábito da polícia, das categorias às quais, supostamente ou não, elas pertencem. É precisamente quando alguns membros da multidão começam a exibir comportamentos hostis que se torna importante tratá-los de modo amistoso, mas nem por isso menos firme. Ou seja, é para frear a violência de uns poucos que se deve ser permissivo com a maioria. Para poder qualificar os diversos componentes da multidão, é preciso de- 
senvolver, dentro da vertente de métodos brandos e de baixo perfil, táticas policiais mais diferenciadas do que as que são usualmente empregadas em grandes concentrações de pessoas.

No seu artigo sobre a formação da guarda urbana (ou municipal) em Buenos Aires, Alina Rios analisa os debates políticos sobre os modelos de policiamento, a construção do problema da insegurança e a "solução de compromisso", entre interesses, mandatos e tecnologias policiais, representada por esta guarda. Inspirando-se na abordagem foucaultiana da "governamentalidade", Rios aborda o poder de polícia como uma questão de orientação de governo, em uma conjuntura de aumento do sentimento de insegurança e clamor público por novas soluções para a manutenção da ordem nos espaços públicos da capital portenha. Sob este enquadramento, a segurança foi refraseada, dentro do discurso da "segurança cidadã" que se resolve por meio de uma série de práticas governamentais produtoras de segurança. Daí a proposta de criação de um modelo de policiamento alternativo - conhecido como polícia comunitária-que emergiu nos EUA e no Canadá, em meados da década de 80 do século passado, de perfil democrático e horizontal - e contraposto ao modelo tradicional da segurança nacional - verticalizado, militarizado e repressivo, adotado em países da America Latina que viveram regimes ditatoriais.

Rios toca no ponto crucial do questionamento da competência exclusiva ambicionada pelas agências policiais (e jurídicas) para definir o que deve ser governado. É assim que, segundo Rios "desde o momento em que uma pluralidade de vozes e espaços é habilitada como palavra séria e espaço legítimo, desde então o saber sobre o que fazer não é exclusivamente policial." (tradução nossa). Como um modo de viver e sentir o ambiente, a experiência da insegurança, nas suas dimensões objetivas e subjetivas, extrapola as categorias jurídicas, apontando para tipos de efeitos que se quer produzir mediante práticas específicas de governo: "A partir dessa perspectiva, a geração de temor compromete a produção de subjetividade e as pautas de interação entre os sujeitos. Ou seja, a produção de sujeitos inseguros passa a fazer parte da agenda governamental e da proposta de um modelo policiamento que atua sobre a segurança objetiva e a sensação de insegurança, mudando a experiência subjetiva dos sujeitos e seus efeitos nas relações sociais." (tradução nossa).

A percepção do castigo entre policiais da Venezuela é o objeto da criminóloga Yoana Monsalves. Nesse estudo preliminar, mas nem por isso pouco acurado, a autora se fundamenta na rica literatura sobre controle social e castigo e uso da força policial para discutir as justificativas dadas por policiais para práticas que extrapolam a sua competência legal. Monsalves argumenta que toda ativação das agências, formais e informais, de controle social de condutas desaprovadas e as sanções contra elas implica alguma forma de castigo ou privação. As agências informais e formais de controle social, entretanto, apresentam diferenças importantes quanto às definições e respostas dadas às condutas inaceitáveis. Enquanto as agências informais primam pela variação de definições e reações, as instâncias formais operam com tipologias pré-estabelecidas e respostas padronizadas ao desvio, comumente previstas em normas de procedimento.

À medida que a polícia possui atribuições e poderes para usar a força e manejar instrumentos visando ao seu exercício, ela pode facilmente praticar, nos mais diversos contextos nacionais, abusos ou excessos contra os cidadãos. Muitos desses excessos implicam o emprego da força como castigo, e não como um recurso instrumental para individualizar, identificar o autor, restringir ou prevenir condutas consideradas como juridicamente inaceitáveis. As condições de possibilidade para isso são os juízos morais de culpabilidade dos suspeitos, a desconfiança no sistema formal de justiça penal, como entidade à qual se reserva a imposição do castigo legal, e a existência de uma demanda social para que os policiais atuem como executores de castigos contra determinadas "clientelas". Embora os 
policiais entrevistados não possuam a mesma compreensão do castigo e dos meios para ministrá-lo, eles o praticam com apoio dos seus colegas de trabalho, de modo informal e com maior ou menor visibilidade, a depender das circunstâncias, contra certos indivíduos e grupos. Um aspecto decisivo para reduzir a possibilidade de castigo é o poder de reclamação do cidadão, traduzido em capacidade de denunciar e processar policiais por essa prática.

A cultura policial relativa às maneiras de as pessoas reagirem e interpretarem as exigências e situações a que estão expostas (Reiner, 2004) é o tema da antropóloga Elizabete Albernaz. O foco do estudo são os encontros, desencontros e reencontros, dentro da organização policial militar, entre a cultura evangélica e a cultura da polícia. Recusando os essencialismos e monolitismos que impregnaram, até o passado recente, os estudos da cultura, Albernaz foca a experiência individual dos policiais evangélicos da atividade policial.

Ao mesmo tempo em que ambas as culturas - evangélica e policial - partilham uma visão maniqueísta do mundo, elas apresentam diferenças marcantes quanto à projeção e tratamento do mal, que influenciam a trajetória dos evangélicos na organização policial. Na experiência dos evangélicos entrevistados, a questão decisiva são as implicações, derivações e excessos do poder da polícia. Se uma parte dos policiais evangélicos se protege disso buscando, dentro de uma linha de baixo perfil, postos de trabalho na "pista" ou nas áreas centrais da cidade do Rio de Janeiro, outros passam a participar de operações arriscadas, nas quais a polícia usa a força para fazer justiça por conta própria. Os esforços dos sujeitos para elaboração dessas sínteses culturais, entretanto, expõem alguns focos de tensões e inconsistências que se revelam, não só na busca do policial evangélico por uma integralidade moral da coerção, mas também no cotidiano de todo policial que tenta evitar as forças corruptoras que emanariam da coerção. Os caminhos e descaminhos dos policiais evangélicos apontam para a sutil fronteira existente entre o arbítrio e a arbitrariedade policial. Para eles, a batalha diária contra o pecado traduz, em termos atemporais, o dilema de produzir respostas policiais eficientes, sem, entretanto, sucumbir aos efeitos corrosivos do poder ou aos "ardis do demônio", segundo os termos da chamada "cultura cristão-evangélica policial".

O artigo da socióloga brasilianista Martha K. Huggins discute as tendências do policiamento público e privado no Brasil. Publicado inicialmente em 2004, na revista Social Justice, esse artigo causou e ainda causa impactos entre os estudiosos. Ainda que de lá para cá os números macabros dos homicídios tenham mudado, as tendências gerais por eles indicadas não são muito diferentes. Ao tomar como ponto de partida os nexos entre a violência letal e a privatização do policiamento, Huggins problematiza a invisibilidade social e a subnotificação dos elevados números de homicídios de brasileiros jovens e adultos, pobres e afrodescendentes. Além de apontar as inevitáveis técnicas de neutralização ou atenuantes morais acionados para justificar essa tragédia social e humanitária em curso, a autora examina as dinâmicas socioinstitucionais produtoras dessas mortes. As taxas de homicídios são mascaradas porque as vítimas são oriundas dos setores já marginalizados da população e por causa do status, oficial ou semioficial, da maioria dos agentes dos assassinatos.

Huggins argumenta que o controle social no Brasil articula dois processos institucionais, aparentemente contraditórios, que ocultam o papel violento do Estado: por um lado, a centralização e militarização da polícia profissional e, por outro, a privatização e descentralização do policiamento. Enquanto a militarização centralizada contribui para encobrir, por meio das ideologias da guerra contra o crime e do profissionalismo (e autonomização das forças policiais), os efeitos das políticas estatais repressivas, a condição mista ou híbrida das empresas de segurança privada - sob o controle ou operadas, em muitos casos, por policiais da ativa, em serviço e 
Jacqueline de Oliveira Muniz,

Eduardo Paes-Machado

fora de serviço - reforça essa ocultação.

A questão posta diz respeito à forma assumida pela estruturação do mercado da segurança privada na sociedade brasileira e, em especial, à falta de fronteiras claras entre esse mercado, incluindo grupos e empresas informais e irregulares, e o policiamento público. Para Huggins, a característica definidora desse controle social privatizado é que ele foi gestado e nutrido no ventre da polícia, com o qual ainda não cortou o seu cordão umbilical. Verifica-se um fluxo facilitado de policiais dentro e fora das empresas de segurança e dos esquadrões da morte, o que evidencia a diluição dos limites reais entre essas entidades de controle social, assim como dificulta o controle público sobre elas. Enfim, a grande variedade de formas assumidas pela privatização do controle social e pela segurança privada contribui para obscurecer o papel do Estado na produção da insegurança socialmente estruturada, assim como o seu fracasso para resolvê-la adequadamente.

(Recebido para publicação em dezembro de 2010)

(Aceito em dezembro de 2010)

\section{REFERÊNCIAS}

BAILEY, D.H.. Padrões de policiamento. São Paulo: Edusp, 2002

BECKER, H.S. Outsiders: studies in the sociology of deviance. New York: Free Press, 1963.

CHEVINY, P. Edge of the knife: police violence in the Americas. New York: The New Press, 1995.

BRODEUR, J.P. Por uma sociologia da força pública: considerações sobre a força policial e militar. Caderno CRH: revista do Centro de Recursos Humanos da UFBA, Salvador, v.17, n.42, p.481-489, set./dez., 2004.

FOUCAULT, M. A governamentalidade. In: MOTTA, Manoel Barros da. Estratégia, poder e saber. Rio de Janeiro: Forense. 2003. v.4 p.281-305. (Ditos \& escritos)

IVO,A.B.L. Viver por um fio: pobreza e política social. São Paulo; Annablume; Salvador: CRH/UFBA, 2008.

JOHNSTON, L. Modernidade tardia, governo e policiamento. In: BRODEUR, J.P. Como reconhecer um bom policiamento. São Paulo: Edusp, 2002. p. 233-257.

LIMA, R.S. de. Palavras e números: violência, democracia e Segurança Pública no Brasil. São Paulo: Alameda, 2010.

McPHAIL, C. The myth of the madding crowd. New York: Aldine de Gruyter, 1991.

MANNING, P. Os estudos sobre a polícia nos países angloamericanos. Caderno CRH: revista do Centro de Recursos Humanos da UFBA, Salvador, v.8, n.45, p.431-446, set./ dez., 2005

MUIR, Jr., K.W. Police: streetcorner politicians. Chicago: Chicago University Press, 1977.

REINER, R. A política da polícia. São Paulo: Edusp, 2004.

Jacqueline de Oliveira Muniz - Antropóloga. Doutora em Ciência Política pelo IUPERJ/ UCAM. Professora do Mestrado em Direito da Universidade Cândido Mendes e da Graduação Tecnológica em Segurança e Ordem Pública (TECSOP) da Universidade Católica de Brasília - UCB. Integra o Grupo de Estudos Estratégicos - GEE/Coppe/UFRJ. Conselheira do Fórum Brasileiro de Segurança Pública. Atua na área de Antropologia e Ciência Política, com ênfase em estudos sobre Segurança Pública e Justiça Criminal, tendo publicado, entre outros, artigo no livro Comércio e segurança pública no estado do Rio de Janeiro (Rio de Janeiro: FECOMERCIO-RJ, 2010 (coletânea de vários autores) e editado (com Haydée Carusoe Antonio Carlos Blanco) a coletânea Polícia, Estado y Sociedad: prácticas y saberes Latinoamericanos (Rio de Janeiro: Publit Seleções Editoriais, 2007), entre outros artigos.

Eduardo Paes-Machado - Professor Associado II do Departamento de Sociologia da Universidade Federal da Bahia (UFBA). Doutor em Ciências Sociais pela UNICAMP, com pós-doutorado na Universidade de Massachusetts (Estados Unidos), e nas Universidades de Toronto (Canadá) e Sheffield e Salford (Grã-Bretanha). Professor nas pós-graduações em Saúde Coletiva, Ciências Sociais e Administração (UFBA). Foi professor visitante da Universidade de Salford. Membro do Laboratório de Estudos em Segurança Pública e Sociedade (LASSOS/UFBA) e do Fórum Brasileiro de Segurança Pública. Suas temáticas de pesquisa são a sociologia do crime, vitimologia, violência relacionada ao trabalho, estudos sobre policiamento, sobre as quais publicou algumas dezenas de artigos e capítulos em revistas e livros nacionais e internacionais. Organizou o livro Poder e Participação Política no Campo (São Paulo, Cerifa, 1987) e o Dossiê Temático Crime, Violência e Justiça (Salvador, Caderno CRH, v. 19, n. 47, 2006). 